\title{
Avoid Junk Food and Start Cycling To School: An Easy Way to Manage Adolescent Obesity
}

\author{
Mohan Joshi ${ }^{1}$, Raghvendra Gumashta ${ }^{2}$, N.B. Kasturwar ${ }^{3}$ Amit Deshpande ${ }^{4}$ \\ ${ }^{1}$ Associate Professor, ${ }^{2,4}$ Resident, ${ }^{3}$ Professor \& Head, Department Of Community Medicine, NKP Salve Institute \\ Of Medical Sciences, Nagpur \\ Corresponding Author: Dr. Raghvendra Gumashta, Department of Community Medicine,N.K.P. Salve Institute \\ of Medical Sciences \& Research Centre, Nagpur (MS)
}

\begin{abstract}
In a cross sectional study carried among 410 mid adolescent school children, about $20.5 \%$ of students were either obese or overweight. Due to their pre-occupation with either studies or tuition, majority (75.4\%) of students had sports activity less than 1 hour daily. Children in nuclear families had higher risk for overweight (18.7\%) as compared to joint families (11.1\%) ( $x^{2}=9.29$ NS). Among adolescents, $1.7 \%$ of male children and $48 \%$ of female children had waist hip ratio above the normal level. The junk food consumption was universal (96\%) due to its easy availability near school premises. The enjoyment of eating effects of advertisements, their delicious taste and peer pressure were the reasons for their high consumption. The daily calorie consumption with mean calorie intake was 2255+203 kcal and 227 (53.37\%) had excess calorie consumption. Amongst the obese subjects, $84.6 \%$ were travelling either by bus or parental automobile, while $15.3 \%$ were either walking or cycling to school and association of obesity with the mode of conveyance was highly significant $\left(x^{2}=230.33\right)$. The simple measure of cycling to school and avoiding junk food consumption could help in control of this modern epidemic of adolescent obesity.
\end{abstract}

Key Words: childhood obesity; daily calorie consumption; junk food consumption; waist hip ratio.

\section{Introduction}

Adolescence is one of the most dynamic stages of human development. It is characterized by an exceptionally rapid rate of growth and is often variable in individual due to its dependence on genetic, hormonal and nutritional factor. Adolescence is accompanied by dramatic physical, cognitive, social and emotional changes that present both opportunities and challenges for adolescents, families, health professionals, educators and communities. Although early life experiences form the foundation for personality development, experiences during the adolescent years contribute significantly to the unique characteristics and maturation of the young adult ${ }^{\mathrm{l}}$.

WHO defines adolescence both in terms of age (spanning the ages between 10 and 19 years) and in terms of a phase of life marked by special attributes. These attributes include rapid physical growth and development, physical, social and psychological maturity, but not all at the same time, sexual maturity and the onset of sexual activity, experimentation, development of adult mental processes and adult identity and transition from total socio-economic dependence to relative independence ${ }^{2}$. The mid adolescence (13-15 years) is distinguished by the development of a separate identity from parents and new relationships with peer groups and opposite sex and of experimentation.

Adolescents comprise approximately one-fifth of the world's population and most of them (84\%) live in developing countries. While the number of adolescents are now significant - more than $20 \%$ of India's population (more than 200 million), they are not a homogeneous group ${ }^{3}$. According to National Family Health Survey -II, India, 1998-99 mid adolescent boys constitute about 5.2\% of total population ${ }^{4}$. Adolescent is characterized by strong tendency to experiment with risk behavior. The desire for novelty and courage for experiment are much greater in adolescent than later life. Most commonly reported behavior in this age group of population include activities such as television viewing, playing video-games, hitting others, lack of sleep and throwing things ${ }^{1}$.

Obesity in childhood has been described as a global epidemic not only in developed but also in developing countries ${ }^{5}$. There are numerous psychological, physical and economic consequences of Childhood obesity $^{6}$. It also affects self esteem and has negative consequences on cognitive and social development of child $^{6,5}$. Conditions such as type II DM, hypertension and hypercholesterolemia, which were noted primarily in adults, are becoming more common among children with a increase in the prevalence of obesity ${ }^{7}$. Because childhood obesity often persists until adulthood, an increasing number of adults will be at an increased risk of these conditions as well as of cardiovascular disease, osteoarthritis and certain types of Cancer. Due to difficulty in the treatment of adult obesity and the many long-term adverse effects of childhood obesity, prevention of childhood obesity has now been recognized as a public health priority ${ }^{7,6,5}$ 
India is also facing the epidemic of obesity and its associated diseases in adolescent. It has been that estimated obesity affects 10-20\% of adolescents in our country. Adolescent are more engaged in indoor activities due to computer, internet and video games. Consumption of junk food is high and low level of physical inactivity make them prone towards many non communicable diseases like obesity, hypertension and diabetes mellitus and at an earlier age. Everyday our adolescents are becoming over conscious about their body images and are often misguided to inculcate unhealthy habits ${ }^{8}$.

Though the majority of national programmes are for children and pregnant women, the adolescents are often the neglected ones ${ }^{4}$. Based on above mentioned observations, it is expected that early detection and intervention in mid adolescent school children should have beneficial effect in preventing the morbidities in mid adolescent school children, who are future adults.

\section{Material \& Method}

The Nagpur Municipal Corporation has ten zone with about 1350 schools within its jurisdiction. Out of these 10 zones, one zone was randomly selected and one school from that zone was selected by lottery method. The sample size of 410 was calculated based on the prevalence of childhood obesity as $8 \%$ (with $95 \%$ CI \& $80 \%$ power) in mid- adolescent children belonging to $12-15$ years age group studying in this school. After explaining the objectives of this study \& its methodology to the concerned authority, their permission was sought. All the students from $7^{\text {th }}, 8^{\text {th }} \& 9^{\text {th }}$ standards who consented for their participation for this study were included as study subjects. All the students who were enrolled were given brief orientation about the purpose of this study, its objective \& its methodology in their class rooms in the presence of their class teachers. The cooperation from class teacher was also sought.

Pre-designed semi structured questionnaire was used as study tool. Study was carried out in morning as well as afternoon hours to get maximum number of study subjects at school without disturbing their academic activity. Two visits were made to ensure maximum participation in the study. Those who were absent were asked to be present at the second visit. Inclusion criteria for study were children of age group 12 to 15 years of age whose parent gave consent. The exclusion criterion was parent who refused consent for the study and chronically absent students. The interview technique was used as a tool for data collection. The pre-tested proforma was used to record the necessary information from the study subjects and separate parental form was sent to the guardian at home to collect necessary information related to socio demographic data like parent education, past history of diseases \& income.

General information and socio-economic details of study subjects were obtained. Food intake was assessed as servings per day by the frequency of intake. Inquiries regarding food habits using closed ended questions were added which included intake at breakfast, lunch and dinner. All detailed information regarding consumption of food at or near school and the frequency and types of fast food consumed one week before their interview were noted. All the students were personally interviewed by the investigator. Another separate format was sent to the parent at home for collecting information regarding education, income, occupation and relevant past $\mathrm{H} / \mathrm{O}$ of any disease. Detailed history was obtained regarding present illnesses. Details were recorded about personal habits like physical activity, mode of conveyance to school, tuition, sport activity, time spent on watching TV, playing video games and operating computer were also recorded. Anthropometric measurements like weight, height, waist circumference, hip circumference and blood pressure measurements were taken and recorded. Anthropometric indicators like Body Mass Index (BMI), Waist-hip ratio (WHpR) were subsequently calculated and entered in the proforma.

The weight was measured using a commercial scale with an accuracy of $\pm 100 \mathrm{gm}$. The subjects were asked to remove their foot wear and wear minimal clothes before weighing them. The standing body height was measured to the nearest $0.5 \mathrm{~cm}$ by using commercial stadiometer with shoulder in a relaxed position and arms hanging freely and without shoes. The scales were recalibrated after each measurement. All the measurements were carried out in a separate room provided by school for this purpose. All the female students were examined in the presence of other female students by female post graduate student from our teaching institute. The Body mass Index (BMI) was calculated as "body weight in kilograms / height in meter $^{2}$ ". We applied the cut off points as recommended by WHO in identifying the age and gender specific cut off points for BMI for the diagnosis of overweight ( $85^{\text {th }}$ percentile) \& obesity $\left(95^{\text {th }}\right.$ percentile) among study subjects, while $<85^{\text {th }}$ percentiles were considered either normal or thin or severe thin according to respective cut off points. The subjects were asked to remove their footwear and wear minimal clothes before weighing them. The study subjects were asked to keep their shoulder in a relaxed position and arms hanging freely and without shoes and weight was recorded in weighing machine.

Waist hip ratio of $\geq 1$ for males $\& \geq 0.85$ for females were taken as specific cut off points for defining obesity. Data was entered in Microsoft excel sheet and analysed using statistical software SPSS version 16 software (SPSS Inc. Chicago, Illinois, USA). Both the descriptive and inferential data analyses were applied 
using the appropriate statistical test of significance (Chi-square, $\mathrm{t}$ - test).The confidence interval of $95 \%$ and significant difference of $\leq 0.05$ is taken as valid for test of significance.

\section{Results}

There are total 410 study subjects of which $237(57.80 \%)$ were male and $173(42.20 \%)$ were female with mean age of $13 \pm 0.71$ yrs. Out of 410 study subjects, maximum number i.e. 189 (46.1\%) father's occupation was in Professional Category followed by $134(32.7 \%)$ in skilled category and the least observed was the category of unemployed (1.5\%). Higher prevalence of professional \& skilled occupation among parents speaks about their affluent status. Maximum number of study subjects had their mother in Housewife Category $279(68 \%)$ followed by professional $(14.9 \%)$ and skilled $(8.4 \%)$. Least number was observed in category of unemployed. This table shows that about $32 \%$ of mothers were in working category. According to modified Kuppuswamy scale, maximum (57.3\%) were from upper middle class followed by upper socio-economic class $(31.9 \%)$ showing predominance of affluent class students amongst the study subjects.

Maximum number of study subjects belong to nuclear families $342(83.41 \%)$ while $45(10.98 \%)$ belong to joint family and only $23(5.61 \%)$ belong to three generation families corresponding to urban pattern of pre dominance of nuclear families. The majority of study subjects were pure vegetarian $(70.4 \%)$, while $29.6 \%$ were having mixed food habits. The majority of study subjects (96\%) were consuming junk foods \& this high prevalence in partly attributed to their socioeconomic status and partly for other factors. Among the study subjects, $89.2 \%$ belong to either upper or upper-middle socioeconomic class and $83.41 \%$ belong to nuclear families. The other reasons could be easy availability, advertisement, delicious taste, peer group pressure, attractive packing and enjoyment of eating such foods particularly in this age group.

Out of total 410 study subjects 214 had more than 1 junk food consumption of which maximum study subjects $178(83.2 \%)$ consumed chocolates followed by candies, pizza and noodles. Least study subjects i.e. 2 $(0.9 \%)$ consumed burger. The probable reason for such distribution could be easy availability of chocolates near school premises and their purchasing capacity in this regard. Out of total 180 study subjects who consume multiple junk foods maximum study subjects 138 (76.7\%) consumed 2 junk foods followed by $32(17.8 \%)$ consumed 3 junk foods. Least study subjects were observed in the category of all junks foods i.e 4(2.2\%).

When the distribution of study subjects was studied according to their daily calorie consumption, calculated by 24 hours recall method, it was noted that out of total study subjects 227 (55.37\%) had excess calorie consumption as per recommended norms for the adolescent. The mean calorie consumption among study subjects was $2255 \pm 203 \mathrm{Kcal} /$ day. The expected daily calorie requirement in the age group of $13-15$ years is $2750 \mathrm{Kcal}$ for boys and $2330 \mathrm{Kcal}$ for girls (A report of expert group of ICMR, 2010). This high percentage of study subjects $(55.37 \%)$ consuming excess calories on a daily basis and high prevalence of study subjects $(96 \%)$ consuming fast foods could be the reason for high prevalence of overweight (17.3\%) and obesity (3.2\%) among them. We also studied these study subjects according to the mode of conveyance to school. (Table 1)

Out of total 410 study subjects maximum study subjects use parental automobile 204(49.76\%) while 81 $(19.76 \%)$ used school bus. Least number of study subjects used walking to reach the school. From above table it is evident about $70 \%$ of study subjects used some or other form of automobile while only $30 \%$ were involved in physical activity that is walking \& cycling to reach the school.

Though walking or cycling was not common mode of conveyance to school, it was most common mode $(74.38 \%)$ for tution. The majority of study subjects $(75.4 \%)$ were spending $<1$ hour for sport activities, while $5.1 \%$ had no time for sports. The television viewing was for $<1$ hour in $75.6 \%$ of study subjects, while video games $(4.1 \%) \&$ computers $(5.3 \%)$ were not their choice for leisure time activities. Though $61 \%$ of study subjects had normal BMI, overweight (17.3\%) and obese (3.2\%) were next common groups. (Fig 1)

In male category only $4(1.7 \%)$ of male study subjects had waist hip ratio more than 1 . While out of 173 female students $90(52 \%)$ were having normal WHR $(<0.85)$, while $83(48 \%)$ were having higher WHR. This higher percentage of WHR among female students could be attributed to puberty spurt commonly noted during mid adolescence in female students or else it indicates abdominal fat accumulation, which may lead to increased risk of metabolic complication in future adult life. Though no significant association is seen in distribution of obesity or overweight in relation to type of family, slight higher number of overweight $(18.7 \%)$ were seen in nuclear families as compared to joint family $(11.1 \%) .\left(\mathrm{X}^{2}=9.2949 \mathrm{df}=8 \mathrm{p}=0.318\right.$ NOT SIGNIFICANT).

It is known that high socioeconomic status and urban residence and adolescent in nuclear families have positive association with intake of high energy foods that could result in overweight and obesity. The subjects in this study are no exception to it. (Table 2) When the study results were analysed for knowing any association between BMI and dietary pattern, no such association was noted. Paradoxically the students having vegetarian diet were more obese $(3.5 \%)$ than those having mixed diet $(2.5 \%)$. Though there was no significant association between obesity or overweight with junk food intake. It may be due to the fact that majority of study subjects $(394 / 410)$ were taking junk food while the comparison group is only small number of subjects $(<4 \%)$ who were non- users. 
It was surprising to note that among obese subjects $84.6 \%$ were travelling either by bus or automobile while $15.3 \%$ were either using cycle or walking as a mode of conveyance to school. There was highly significant association between obesity among study subjects and conveyance by automobile, and the students needs to be educated in this regard. The simple measure of using cycle as a vehicle of conveyance to school can help them to control their overweight and obesity. (Table 3)

When we associated the distribution of study subjects according to sports activity in hours and waist hip ratio in male and female study subjects. Out of total 237 male study subjects only $1.7 \%$ of male subjects had $\mathrm{W} / \mathrm{H}$ ratio more than 1 . When we compare male study subjects according to sports activity in hours and W/H ratio higher proportion of study subjects spend less than 1 hour in sports activity as compared to who spent more than 1 hour in sports activity. This difference is found to be statistically significant. In 173 female study subjects $48 \%$ had W/H ratio more than 0.85 . Maximum proportion of study subjects were spending less than 1 hour in sports activity as compared to other group, however this difference is found to be statistically not significant. (Table 4) Though $288(70.2 \%)$ were normotensive, pre-hypertension was noted in 65(15.9\%) and hypertension was noted in 57(13.9\%) adolescent study subjects, which is a serious danger signal for them.

The high prevalence of prehypertension and stage I hypertension as seen among these study subjects could be due to the fact that hypertension was screened only once during study protocol. It is advisable that students with blood pressure $>95^{\text {th }}$ percentile on first screening should undergo a second screening 1 to 2 weeks later and then a third screening if blood pressure is noted $>95^{\text {th }}$ percentile at the second screening. But this could not be practised as the study subjects were preoccupied for their academic engagements and school authorities denied permission for such repeat screenings, hence this becomes a limitation of this study. The prevalence of pre-hypertension \& stage I hypertension is seen to be significantly increasing with age from 12 yrs to 14 yrs. This could be taken as an indicator for tracking adult hypertensives in future.

Though $74 \%$ of female students and $67.5 \%$ of male students were having normal systolic blood pressure there is alarming percentage of pre-hypertensive and stage I hypertensive both among male \& female students. The gradient of pre-hypertension is upwards along with age of students even the stage I hypertension particularly in male students in gradually increasing with their age. This is of grave epidemiological concern knowing that tracking of hypertension from childhood to adult life is known epidemiological phenomenon. This is a grave signal for hypertensive epidemic in near future in younger population. (Table 5)

\section{Discussion}

Among the study subjects, consumption of junk food was universal (96\%) and about $43.9 \%$ were consuming multiple junk foods. Majority of study subjects $(89.2 \%)$ were belonging to either upper or upper middle socio-economic category and easy availability of fast foods near school premises obviously resulting in high consumption of these fast food. Shi Z et al $(2005)^{9}$ : conducted a cross sectional study among 824 adolescent school children to identify the differences in food habits and found that more than half of the students reported a liking for western style fast foods excluding hamburgers, soft drinks and chocolate. Among study subjects $10 \%$ of high SEC boys were consuming fast food as compared to only $2.8 \%$ in low SEC students. Singh P $(2008)^{10}$ has conducted a study to find out feeding habit of adolescent girls outside their houses in Varanasi city. Nearly $2 / 5^{\text {th }}$ of adolescent girls consumed cake, pastry, sandwich, chocolate and sweet followed by cold drinks, ice-cream and kulfi(34.33\%). The fast food like pizza, burger, pavbhaji and Manchurian were consumed by $33 \%$ of students. Seema Jain et al (2010) ${ }^{11}$ conducted school based cross sectional study in Meerut and reported obesity to be significantly associated with high intake of junk foods $(\mathrm{P}<0.05)$ apart from lower physical activity $(\mathrm{p}<0.05)$ and prolonged TV watching $(\mathrm{p}<0.05)$

Daily calorie consumption was calculated by $24 \mathrm{hrs}$ recall method. 227 (55.37\%) had excess calorie consumption as per recommended norms for the adolescent. In this study daily calorie consumption with mean calorie intake was $2255 \pm 203 \mathrm{Kcal}$. The international children's centre at Paris in their report No. 151, titled "Children in tropics" has calculated that a child whose energy requirement is $2000 \mathrm{Kcal} /$ day and who consumes $100 \mathrm{kcal} /$ day extra will gain about 5 kilograms a year. The cumulative accumulation of 7,700 kcal of energy results in accumulation of one kilo of fat is known phenomenon and is associated with high prevalence of overweight and obesity among such population.

The majority of study subjects (69.52\%) were either using parental automobile or school bus for reaching their school and $75.4 \%$ were spending less than one hour on their sports activities. Ashley R Cooper et al $(2003)^{12}$ conducted a record based study and found that of the 114 children's (59 body, 55 Girls, aged $10.4 \pm$ 0.8 years) who took part in the study walked to school $(65 \%)$. Their hourly activity patterns demonstrated that boys who walked to school were more active after school and throughout the evening than those who were car users.

Overall Prevalence of obesity in study subjects was found $3.2 \%$ and overweight $17.3 \%$. The obesity observed was more in age group 15 years. The prevalence of obesity was more in female $4 \%$ as compared to male $2.5 \%$. It has been noted that the percentage of overweight is increasing with advancing age. Though $61 \%$ were having 
normal body mass index (BMI) $17.3 \%$ (nearly $1 / 5^{\text {th }}$ ) were overweight. It was more in male study subjects $21.5 \%$ as compared to female $11.6 \%$.

Elizabeth $\mathrm{KE}(2001)^{13}$ conducted a cross sectional study among 500 adolescent boys and girls in age group in 13-19 years and revealed that $79 \%$ of them were within the bold lines of the normal health path, $11 \%$ were underweight with borderline chronic energy deficiency(CED) and $<1 \%$ had severe chronic energy deficiency. Among this study population $10 \%$ were overweight and $<1 \%$ had overt obesity. Dietz WH(2004) ${ }^{14}$ found that the prevalence of overweight doubled among children in 6-11 years of age group and tripled among those between 12-17 years of age. It was also reported that although only $25-30 \%$ of obesity in U.S. adults begins during childhood or adolescence, early childhood overweight that persist into adulthood is associated with more severe obesity among adults. Wang $\mathrm{Y}$ et al $(2002)^{15}$ conducted a cross sectional study to know the trends of overweight and underweight in adolescents in different countries. The annual rate of increase in the prevalence of overweight increased during the study period in Brazil(from 4.1 to 13.9), China(from 6.4 to 7.7) and the United States( from 15.4 to 25.6), while in Russia overweight decreased from 15.6 to 9.0.

Al Sendi AM et al $(2003)^{16}$ conducted a cross sectional study among 506 school in Bahrain to report the prevalence of obesity to be $21 \%$ in males and $35 \%$ in females according to WHO criteria and $15 \%$ in boys and $18 \%$ in girls according to Cole et al criteria. Seema Jain et al $(2010)^{11}$ in their study among 2785 affluent adolescent school children also reported prevalence of overweight and obesity as $19.7 \%$ and $5.3 \%$ in girls and $18.36 \%$ and $10.82 \%$ among boys respectively. Tarek Tawfik Amin $(2008)^{17}$ conducted a cross sectional descriptive study in 1139 Saudi Arabic male Children in public primary school at Al Hassa to report the prevalence of overweight as $14.2 \% \&$ that of obesity as $9.7 \%$ particularly among urban older age students. This high prevalence of overweight and obesity was related with working and less educated mothers, unhealthy dietary habits and poor selection of food that is more fast food intake.

Though severe academic anxiety was commonest morbidity (20.2\%), overweight (17.3\%) and Stage 1 Hypertension (11.5\% 0 were other commonest morbidities prevalent among study subjects.

Jonathan M. Sorof et al (2004) $)^{18}$ performed school based screening in 5102 children to report the prevalence of elevated blood pressure after first screening as $19.4 \%$ which was highest among Hispanics (25\%) and lowest among Asians (14\%). The relative risk of hypertension was significant for gender (RR-1.50) and overweight (RR- 3.26) McNiece KL et al (2007) ${ }^{19}$ in their cross sectional study among 6790 adolescents (11-17 years) reported prevalence of prehypertension as $15.7 \%$, stage I hypertension as $2.6 \%$ and stage II hypertension as $0.6 \%$. They found that overweight and increasing BMI were independently associated with prehypertension and hypertension among adolescent school children. The finding of our study are similar to this study. Fuiano $\mathrm{N}$ et al $(2007)^{20}$ performed school based screening in 1563 children (3-16 years) and reported the prevalence of elevated blood pressure at first, second and third screening was $35.1 \%, 33.8 \%$ and $23.9 \%$ in males and $41 \%, 40.2 \%$ and $31.2 \%$ in females with relative risk significantly high for overweight subjects.

\section{Conclusion}

The results of this cross sectional study carried out in elite urban school of metropolitan city of Nagpur clearly speaks about high prevalence of junk food consumption, overweight, severe academic anxiety, stage I hypertension and prevalent sedentary life styles in mid-adolescent study subjects. All these patterns could be logically trekked to young adult population and is a cause of concern for everyone. The public health researchers all over the world speaks about life style modification as a tool for the control \& prevention of modern epidemics of non communicable diseases posing a great challenge for developed and developing countries. But the question remains when \& where to start for these life style modification. The present study is giving clear evidence in this regard. The school campus remains the powerful place where these adolescents could be provided with seeds for these interventions directed towards future life style modifications. Avoiding the junk food and instead replacing it with fruits and salads would help them in a long way. The simple act of cycling to school instead of using automotive would imbibe the healthy habit of having regular physical exercise activity in daily schedule of these adolescents and would help them in attaining secured \& healthy future.

\section{References}

[1] World Health Organization. Health problems of adolescence. Technical Report Series No.308, 1965:3-28.

[2] World Health Organization. Department of child and adolescent Health and development what about boys. A Literature Review on the Health and Development of Adolescent Boys: 7-11 (http://www.ncbi.nlm.nih.gov/entrez/query.fcgi)f.

[3] Bezberruah S, Janeja MK. Adolescents in India : A profile. UNFPA, New Delhi 2000: 3-5.

[4] J. Kishore's. National health programmes of India. National policies and legislation related to health. $9^{\text {th }}$ edition, 2011. Century publication, New Delhi.

[5] World Health Organisation. Obesity: Preventing and managing the global epidemic, Technical Report Series 894. 2000. p-1-2.

[6] WHO: Global prevalence \& secular trends in obesity in:”Obesity Preventing \& managing the Global epidemic. Report of a WHO consultation on Obesity" Geneva: WHO; 1998.p-17-40.

[7] NCD. World Health Organization- Regional Office for South- East Asia Region (SEAR), Dated 4/17/2007.

[8] World Health Organization. Physical status: use and interpretation of anthropometry. Technical report series No.854, 1995. 
[9] Shi Z, Lien N, Kumar BN, Holmboe, Ottesen G. Socio Demographic differences in food habits and preferences of school adolescents in Jiangsu Province, China. Eur j Clin Nutr. 2005,; 59(12):1439-48.

[10] Singh P, Singh A. Increasing allurement for fast food in adolescent girls of urban area, Varanasi. Indian journal of preventive and social medicine. 2008 ; 39(1-2): 24-27.

[11] Seema Jain, Bhawna Pant, h. Chopra, R. Tiwari Obesity among adolescent of Affluent public schools in Meerut. Indian Journal of public Health. 2010; 54(3):158-160.

[12] Ashley R Cooper, Angie S Page, Wey J Foster, Dino Qahwaji. Commuting to school. American Journal of Preventive Medicine. 2003 Nov; 25(4):273-276.

[13] Elizabeth KE. A novel growth assessment chart for adolescent. Indian journal of Pediatrics. 2001; 38:1061-4.

[14] Deitz WH. Overweight in childhood \& adolescence. New England J. Med 2004; 350:855-7.

[15] Wang Y, Monterio CA, Popkin BM. Trend of obesity \& underweight in older children and adolescents in the USA, Brazil, China \& Russia. Am J public Health. 2004; 94(9):1544-1548.

[16] Al Sendi AM, Shetty P, Musaiger MO. Prevalence of overweight and obesity among Bahraini adolescents a comparison between three different sets of criteria. Eur J Clin Nutr. 2003; 57(3): 471-474.

[17] Tarek Tawfik Amin, Ali Ibrahim Al Sultan, Ayub Ali. Over weight and Obesity and their Association with Dietary Habits and Socio demographic characteristics among Male Primary School children in Al Hassa, Kingdom of Saudi Arbia. Indian Journal of community Medicine. 2008; 33(3):172-181.

[18] Jonathan M. Sorof, Dejian Lai, Jennifer Turner, Tim Poffenbarger, Ronald J. Portman. Overweight, ethnicity and the prevalence of hypertension in school aged children. Pediatrics 2004; 113;475.

[19] McNiece KL, Poffenbarger TS, Turner JL, Franco KD, Sorof JM, Portman RJ.. Prevalence of hypertension and prehypertension among adolescents. The journal of Pediatrics, 2007; 150(6): 640-644.

[20] Fuiano N, Luciano A, Pilotto L, Pietrobelli A. Overweight and hypertension: longitudinal study in school aged children. Minerva Pediatrics. 2006 oct; 58(5): 451-9.

\section{Table 1: Distribution of Study Subjects according to Mode of Conveyance to School}

\begin{tabular}{|c|c|c|}
\hline Mode of Conveyance & Number & Percentage (\%) \\
\hline Bus & 81 & 19.76 \\
\hline Automobile* & 204 & 49.76 \\
\hline Walking & 21 & 5.12 \\
\hline Cycling & 104 & 25.36 \\
\hline Total & 410 & 100 \\
\hline
\end{tabular}

* automobile includes 3 wheeler, auto rickshaw \& parental vehicle

Table 2: BMI percentile according to Type of family

\begin{tabular}{|c|c|c|c|c|c|c|}
\hline Family & Normal & Obese & Over weight & Severe Thinness & Thinness & Total \\
\hline Joint & $26(57.8 \%)$ & $4(8.9 \%)$ & $5(11.1 \%)$ & $3(6.7 \%)$ & $7(15.6 \%)$ & $45(100.0 \%)$ \\
\hline Nuclear & $207(60.5 \%)$ & $8(2.3 \%)$ & $64(18.7 \%)$ & $19(5.6 \%)$ & $44(12.9 \%)$ & $342(100.0 \%)$ \\
\hline Three Generation & $17(73.9 \%)$ & $1(4.3 \%)$ & $2(8.7 \%)$ & $1(4.3 \%)$ & $2(8.7 \%)$ & $23(100.0 \%)$ \\
\hline Total & $250(61.0 \%)$ & $13(3.2 \%)$ & $71(17.3 \%)$ & $23(5.6 \%)$ & $53(12.9 \%)$ & $410(100.0 \%)$ \\
\hline
\end{tabular}

Table 3:Distribution of BMI percentile with Mode of Conveyance to school

\begin{tabular}{|c|c|c|c|c|c|}
\hline \multirow{2}{*}{ BMI (percentile) } & \multicolumn{4}{|c|}{ Mode of conveyance to school } & \multirow{2}{*}{ Total } \\
\hline & Bus & Cycle & Parental Automobile & Walking & \\
\hline Normal & $52(20.8 \%)$ & $61(24.4 \%)$ & $129(51.6 \%)$ & $8(3.2 \%)$ & $250(100 \%)$ \\
\hline Obese & $6(46.1 \%)$ & $2(15.3 \%)$ & $5(38.6 \%)$ & $0(0 \%)$ & $13(100 \%)$ \\
\hline Overweight & $6(8.4 \%)$ & $28(39.4 \%)$ & $28(39.4 \%)$ & $99(12.7 \%)$ & $71(100 \%)$ \\
\hline Severe Thinness & $5(21.7 \%)$ & $3(13.1 \%)$ & $15(65.2 \%)$ & $0(0 \%)$ & $23(100 \%)$ \\
\hline Thinness & $12(22.6 \%)$ & $10(18.9 \%)$ & $27(50.9 \%)$ & $4(7.6 \%)$ & $53(100 \%)$ \\
\hline Total & $81(19.7 \%)$ & $104(25.4 \%)$ & $204(49.7 \%)$ & $21(5.2 \%)$ & $410(100 \%)$ \\
\hline
\end{tabular}


Avoid Junk Food And Start Cycling To School: An Easy Way To Manage Adolescent Obesity

Table 4: Distribution of Study Subject according to Waist Hip Ratio \& time spent for sports activity

\begin{tabular}{|c|c|c|c|c|c|c|c|}
\hline $\begin{array}{c}\text { Waist } \\
\text { Hip } \\
\text { Ratio }\end{array}$ & $\begin{array}{c}\text { Male } \\
(\boldsymbol{\%})\end{array}$ & $\begin{array}{c}\text { Sport } \\
\text { activity }<\mathbf{1} \\
\mathbf{h r}\end{array}$ & $\begin{array}{c}\text { Sport } \\
\text { activity } \\
>\mathbf{1 ~ h r}\end{array}$ & $\begin{array}{c}\text { Waist } \\
\text { Hip } \\
\text { Ratio }\end{array}$ & $\begin{array}{c}\text { Female } \\
(\mathbf{\%})\end{array}$ & $\begin{array}{c}\text { Sport } \\
\text { activity } \\
<\mathbf{1} \text { hr }\end{array}$ & $\begin{array}{c}\text { Sport } \\
\text { activity }>\mathbf{1} \\
\text { hr }\end{array}$ \\
\hline$<1$ & $233(98.3 \%)$ & $196(84.1 \%)$ & $37(15.9 \%)$ & $<0.85$ & $90(52 \%)$ & $24(26.7 \%)$ & $66(73.3 \%)$ \\
\hline$>1$ & $04(1.7 \%)$ & $01(25 \%)$ & $03(75 \%)$ & $>0.85$ & $83(48 \%)$ & $13(15.7 \%)$ & $70(84.3 \%)$ \\
\hline Total & $\mathbf{2 3 7 ( 1 0 0 )}$ & $\mathbf{1 9 7}(\mathbf{8 3 . 1 \%})$ & $\mathbf{4 0 ( 1 6 . 9 \% )}$ & & $\mathbf{1 7 3 ( 1 0 0 )}$ & $\mathbf{3 7}(\mathbf{2 1 . 4 \% )}$ & $\mathbf{1 3 6 ( 7 8 . 6 \% )}$ \\
\hline
\end{tabular}

For Male $\quad X^{2}=9.7974 \mathrm{p}=0.016$ Significant

For Female $\quad \mathrm{X}^{2}=3.1098 \mathrm{p}=0.0778$ Non-Significant

Table 5:_Age \& Gender wise distribution of SBP percentile

\begin{tabular}{|c|c|c|c|c|c|c|c|c|c|c|}
\hline \multicolumn{6}{|c|}{ Hypertension ( Male) } & \multicolumn{5}{|c|}{ Hypertension ( Female) } \\
\hline $\begin{array}{c}\text { Age } \\
\text { (in } \\
\text { years) }\end{array}$ & Normal & Pre-HT & $\begin{array}{l}\text { Stage } \\
\text { I HT }\end{array}$ & $\begin{array}{c}\text { Stage II } \\
\text { HT }\end{array}$ & TOTAL & Normal & Pre-HT & $\begin{array}{l}\text { Stage } \\
\text { I HT }\end{array}$ & $\begin{array}{c}\text { Stage II } \\
\text { HT }\end{array}$ & $\begin{array}{c}\text { TOTA } \\
\text { L }\end{array}$ \\
\hline 11 & $0(0)$ & $0(0)$ & 1 & $0(0)$ & $1(100)$ & $1(100)$ & $0(0)$ & $0(0)$ & $0(0)$ & $1(100)$ \\
\hline 12 & $19(79.2)$ & $0(0)$ & $5(20.8)$ & $0(0)$ & $24(100)$ & $14(82.4)$ & $1(5.9)$ & $1(5.9)$ & $1(5.9)$ & 17 \\
\hline 13 & $74(78.7)$ & $13(13.8)$ & $7(7.4)$ & $0(0)$ & $94(100)$ & $83(79.8)$ & $17(16.3)$ & $3(2.9)$ & $1(1)$ & $\begin{array}{c}104(100 \\
)\end{array}$ \\
\hline 14 & $65(58.6)$ & $20(18)$ & $22(19.8)$ & $4(3.6)$ & $111(100)$ & $28(60.9)$ & $11(23.9)$ & $3(6.5)$ & $4(8.7)$ & $46(100)$ \\
\hline 15 & $2(28.6)$ & $1(14.3)$ & $4(57.1)$ & $0(0)$ & $7(100)$ & $2(40)$ & $2(40)$ & $1(20)$ & $O(0)$ & $5(100)$ \\
\hline Total & $\begin{array}{c}160(67 . \\
5)\end{array}$ & $34(14.3)$ & $39(16.5)$ & $4(1.7)$ & $237(100)$ & $128(74)$ & $31(17.9)$ & $8(4.6)$ & $6(3.5)$ & $\begin{array}{c}173(100 \\
)\end{array}$ \\
\hline
\end{tabular}

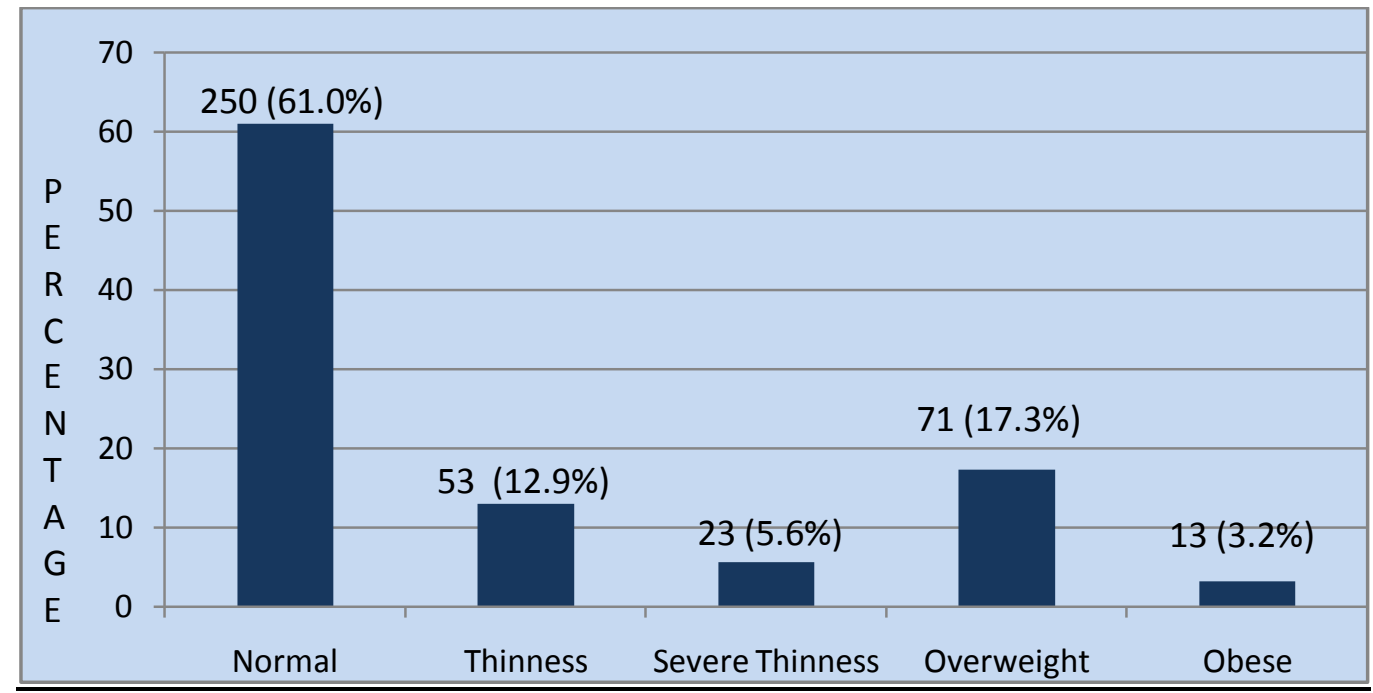

Fig. 1 Bar Diagram showing distribution of study subjects according to body mass index 